\title{
STAR mutations causing non-classical lipoid adrenal hyperplasia manifested as familial glucocorticoid deficiency
}

\author{
YUANYUAN LUO ${ }^{1}$, RUOJING BAI $^{2}$, ZHIFANG WANG $^{3}$, XIAOFAN ZHU $^{4}$, JINGJING XING $^{3}$ and XIALIAN LI ${ }^{3}$ \\ ${ }^{1}$ Department of Geriatrics, The First People's Hospital of Yunnan Province, \\ The Affiliated Hospital of Kunming University of Science and Technology, Kunming, Yunnan 650032; \\ ${ }^{2}$ Department of Medical Technology, Beijing Health Vocational College, Beijing 100053; \\ ${ }^{3}$ Department of Endocrinology and Metabolism, The First Affiliated Hospital of Zhengzhou University, \\ Zhengzhou, Henan 450052; ${ }^{4}$ Department of Genetic and Prenatal Diagnosis Center, \\ Chinese University of Hong Kong, Hong Kong 999077, SAR, P.R. China
}

Received July 22, 2019; Accepted March 31, 2020

DOI: $10.3892 / \mathrm{mmr} .2020 .11140$

\begin{abstract}
Familial glucocorticoid deficiency (FGD) is a rare autosomal recessive disease characterized by single cortisol deficiency but normal aldosterone and renin levels. Beginning from the discovery of the disease to that of the pathogenic genes over a period of 30 years, the development of gene detection technology has identified a large number of FGD-related genes. Despite the fact that the genetic defect underlying this disease is known for approximately $70 \%$ of the patients diagnosed with FGD, there are still several unknown factors causing it. FGD is divided into type 1, type 2 and non-classical type according to the mutant gene. The case described in the present study reported two patients, who were siblings, having skin hyperpigmentation and undergone treatment in adulthood. The gonadal development was normal and the proband had a 10-year-old son. Laboratory tests suggested glucocorticoid deficiency and a mild lack of mineralocorticoid, indicating hyponatremia and hypotension in the proband. In addition, cortisol deficiency was not affected by adrenocorticotropic hormone treatment, while the adrenal glands in the two patients did not show any hyperplasia. Gene analysis revealed two compound heterozygote mutations c.533T $>$ A (p. Leu178Gln) and c.737A $>\mathrm{G}$ (p. Asp246Gly) in the steroid hormone acute regulatory protein $(S T A R)$ gene in both patients, which may have been obtained from their parents and the proband passed one of the mutations to her son. The present study results revealed that STAR mutations cause non-classic congenital lipoid adrenal hyperplasia in China.
\end{abstract}

Correspondence to: Professor Xialian Li, Department of Endocrinology and Metabolism, The First Affiliated Hospital of Zhengzhou University, 1 Eastern Jianshe Road, Zhengzhou, Henan 450052, P.R. China

E-mail: xialianli1962@163.com

Key words: familial glucocorticoid deficiency, gene detection, STAR gene mutation

\section{Introduction}

Familial glucocorticoid deficiency (FGD) was reported for the first time by Shepard et al (1), in 1959. The study described a case of two sisters who presented adrenal insufficiency, cortisol hormone deficiency and normal levels of aldosterone, renin, skin hyperpigmentation, muscle weakness and other performances. In addition, the serum electrolytes and blood pressure were normal and the cortisol (COR) levels were not affected by the treatment with adrenocorticotropic hormone (ACTH). Hitherto, the identified FGD-related genes were the following: Melanocortin 2 receptor/ACTH receptor $(M C 2 R)(2), M C 2 R$ accessory protein $(M R A P)(3)$, nicotinamide nucleotide transhydrogenase $(N N T)(4)$, the minichromosome maintenance-deficient 4 homolog gene (MCM4) (5), thioredoxin reductase (TXNRD2) (6), steroid hormone acute regulatory protein $(S T A R)$ (7) and cytochrome P450 family 11 subfamily A polypeptide 1 (CYP11A1) (8). Of these, $M C 2 R$ and $M R A P$ accounted for $50 \%$ of all the mutations.

The $S T A R$ gene encodes a steroid acute regulatory protein that serves a key function in the steroid synthesis. In this process, cholesterol is presented to the cytochrome $\mathrm{P} 450 \mathrm{scc}$ encoded by the CYPIIAl gene, catalyzing the cholesterol to pregnenolone, which regulates the supply of substrate cholesterol from the mitochondrial outer membrane to the underlying mitochondrial membrane. The gene mutation effectuates as early onset and causes severe steroid hormone deficiency, hypoglycemia, loss of salt, dysplasia and adrenal lipid deposition $(9,10)$, usually within a few months after birth.

Some non-classical mutations can retain certain features, resulting in FGD clinical manifestations, such as that of the two sibling patients described in this article. Interestingly, they demonstrated the clinical diagnosis as primary adrenal insufficiency (PAI) but with normal gonadal function and adrenal hyperplasia. The c.533T $>$ A (p. Leu178Gln) and c.737A $>$ G (p. Asp246Gly) mutations in the STAR gene were obtained from the parents and confirmed by the second-generation sub-whole exon gene sequencing. 


\section{Case report}

Patient 1. A normal female 34-year-old proband was the first-born child of non-consanguineous parents. The patient was admitted to The First Affiliated Hospital of Zhengzhou University in March 2017 because of skin pigmentation experienced for 32 years, low blood pressure for 6 years and intermittent nausea and vomiting for 6 months. The patient was born in 1982 after an uneventful pregnancy. At the age of two, the patient suffered from upper respiratory tract infection several times and skin hyperpigmentation gradually started to appear. Pubertal development started at the age of 11 , menarche was presented at 13 and currently (in 2018), the patient has a 10-year-old son. The patient was diagnosed with 'bipolar affective disorder' 4 years ago and was treated with oral medication such as lithium carbonate, lorazepam, sertraline and buspirone. The karyotype of the patient was 46, XX with skin hyperpigmentation (Fig. 1A); however, the breasts and vulva were normal. Blood pressure was $80 / 40 \mathrm{mmHg}$, fasting blood glucose was 3.9 (normal range: $3.6-6.1) \mathrm{mmol} / \mathrm{l}$, serum sodium was $126 \mathrm{mmol} / \mathrm{l}$ (normal range: $135-155 \mathrm{mmol} / \mathrm{l}$ ), 17-hydroxyprogesterone (17-OHP) was $0.31 \mathrm{ng} / \mathrm{ml}$, dehydroepiandrosterone (DHEA) was $<15$ (normal range: $35-430$ ) $\mu \mathrm{g} / \mathrm{dl}$, normal serum gonadotropin concentrations for follicle stimulating hormone (FSH) and luteinizing hormone ( $\mathrm{LH})$ were 5.36 and $5.83 \mathrm{mIU} / \mathrm{ml}$, respectively, the lying position renin-angiotensin-aldosterone system (RAAS) showed that renin activity was $>26.68$ (normal range: $0.15-2.33$ ) $\mathrm{ng} / \mathrm{ml} . \mathrm{h}$, angiotensin II was 232.0 (normal range: $25-80) \mathrm{pg} / \mathrm{ml}$ and aldosterone was 153.0 (normal range: $30-160) \mathrm{pg} / \mathrm{ml}$. ACTH-COR rhythm is listed in Table I. The 24-h urine-free cortisol (UFC) was 83 (normal range: 73-372) $\mathrm{nmol} / \mathrm{l}$. The cortisol levels did not respond to the stimulation with ACTH (250 $\mu \mathrm{g}$ intravenous injection in $1 \mathrm{~min})$ (Table II). Computed tomography (CT) revealed bilateral adrenal glands without hyperplasia and the left side presented calcification (Fig. 2A).

Patient 2. The younger brother of patient 1 was born in 1992 after an uneventful pregnancy. The patient displayed skin hyperpigmentation from childhood and occasional fatigue. The karyotype of the patient was 46, XY. Pubertal development started at the age of 14 years. Skin hyperpigmentation (Fig. 1B) by the Tanner staging of testis was 4 , and the patient was unmarried. Normal blood glucose, serum electrolytes, serum gonadotropin concentrations: FSH 6.12 (normal range: 0.95-11.95) $\mathrm{mIU} / \mathrm{ml}$ and LH 4.95 (normal range: 1.14-8.75) $\mathrm{mIU} / \mathrm{ml}$, DHEA was 58.2 (normal range: $80-560) \mu \mathrm{g} / \mathrm{dl}$ and lying position RAAS: Renin activity was $22.95 \mathrm{ng} / \mathrm{ml} . \mathrm{h}$, angiotensin II was $73.27 \mathrm{pg} / \mathrm{ml}$, aldosterone was $151.7 \mathrm{pg} / \mathrm{ml}$. ACTH-COR rhythm is listed in Table I; the 24-h UFC was $134 \mathrm{nmol} / \mathrm{l}$. CT did not reveal any hyperplasia in the bilateral adrenal glands (Fig. 2B).

Genomic DNA was extracted from the peripheral blood of the two patients and their familial relatives (parents and son of the proband) after written informed consent (the patients agreed to blood sampling, gene testing, publication of their data and figures). Sub-whole exon gene sequencing was performed using Exon Chip Capture (Agilent Technologies, Inc.) and high-throughput sequencing (Beijing Jinzhun Gene Technology
Table I. ACTH-COR rhythm of the two patients.

A, ACTH $(\mathrm{pg} / \mathrm{ml})$

\begin{tabular}{lccc}
\hline Patient & $8: 00$ & $16: 00$ & $00: 00$ \\
\hline Patient 1 & $>1,250$ & $>1,250$ & $>1,250$ \\
Patient 2 & $>1,250$ & $>1,250$ & - \\
\hline
\end{tabular}

$\mathrm{B}, \mathrm{COR}(\mathrm{ng} / \mathrm{ml})$

\begin{tabular}{lccc}
\hline Patient & $8: 00$ & $16: 00$ & $00: 00$ \\
\hline Patient 1 & 201 & 189 & 151 \\
Patient 2 & 312 & 186 & - \\
\hline
\end{tabular}

ACTH, adrenocorticotropic hormone; COR, cortisol; -, not applicable.

Table II. ACTH stimulation test of patient 1.

\begin{tabular}{lccc}
\hline Variable & 0 min & $30 \mathrm{~min}$ & $60 \mathrm{~min}$ \\
\hline COR $(\mathrm{ng} / \mathrm{ml})$ & 246 & 231 & 263 \\
17-OHP $(\mathrm{ng} / \mathrm{ml})$ & 0.31 & 1.82 & 2.05 \\
DHEA $(\mu \mathrm{g} / \mathrm{dl})$ & $<15$ & 21.7 & 20.8 \\
Androstenedione $(\mathrm{ng} / \mathrm{ml})$ & $<0.3$ & 0.6 & 0.5 \\
\hline
\end{tabular}

ACTH, adrenocorticotropic hormone; COR, cortisol; OHP, hydroxyprogesterone; DHEA, dehydroepiandrosterone.

Co., Ltd). Sequences of the mutations were aligned against that in the National Center for Biotechnology Information (NCBI) database. The data interpretation was according to the guidelines of the American College of Medical Genetics and Genomics (ACMG) and variations were named according to the recommendations of the Human Genome Variation Society (HGVS; www.hgvs.org/mutnomen). The protein was predicted by Polyphen2, Sorting Intolerant From Tolerant (SIFT) and Protein Variation Effect Analyzer (PROVEAN) software and SWISS-MODEL was used to construct the protein model. Alterations in the protein structure and amino acid hydrogen bond were analyzed before and after the mutation.

The patients were treated with oral administration of $20 \mathrm{mg}$ hydrocortisone (HC) in the morning and $10 \mathrm{mg}$ in the evening. Indicators such as skin pigmentation, appetite, blood pressure, ACTH, serum cortisol, serum electrolytes and blood glucose were monitored regularly and the $\mathrm{HC}$ dose was changed according to the symptoms and the results of testing.

Two heterozygote mutations c.533T>A (p. Leu178Gln) and c.737A $>\mathrm{G}$ (p. Asp246Gly) were found on the STAR gene in the two patients; one was passed from each parent, respectively, and the son of the proband carried one of the mutations (Fig. 3). The sequencing of the peak pattern revealed an additional peak that was further verified by the first generation of gene sequencing (Fig. 4). The amino acid 

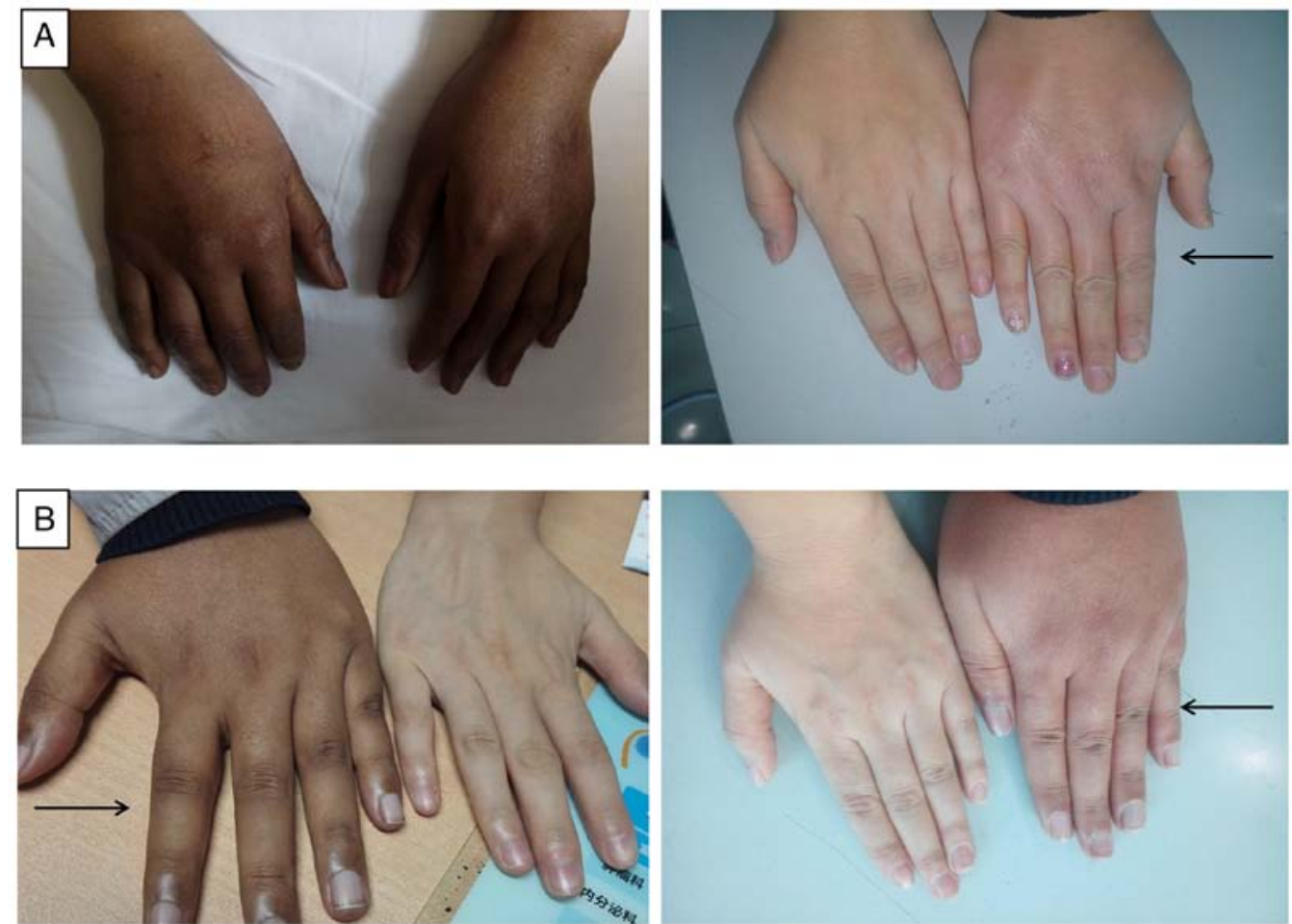

Figure 1. Changes in the skin pigmentation of the two patients before and after treatment. The image with the arrow is compared to the normal individuals and arrow refers to the patient. (A) Patient 1, skin hyperpigmentation is reduced after treatment. (B) Patient 2, skin hyperpigmentation is reduced after treatment.
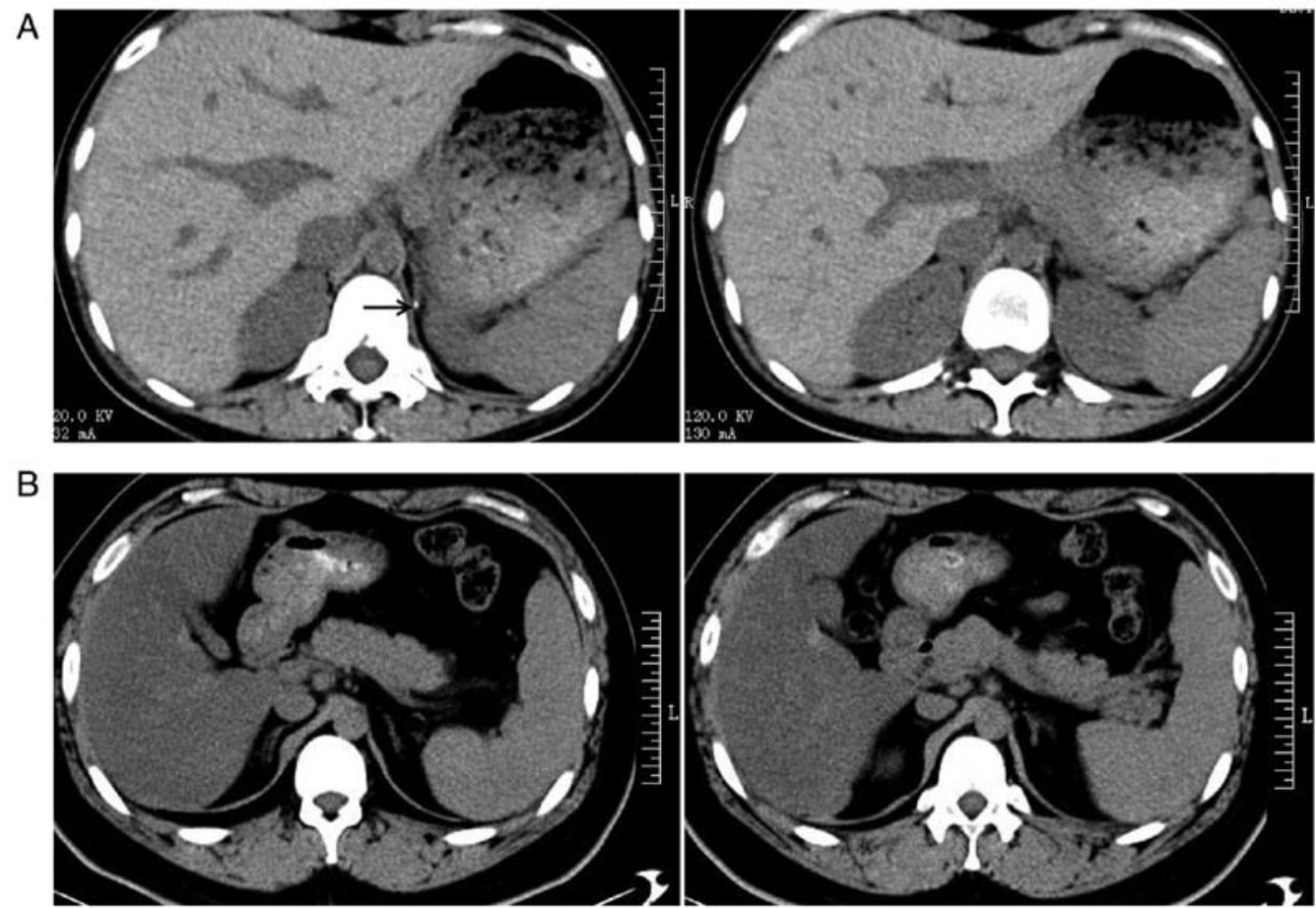

Figure 2. Adrenal CT real-time imaging examination of the patients. (A) Patient 1, no hyperplasia in bilateral adrenal glands and the left arrow indicates calcification. (B) Patient 2, no hyperplasia in bilateral adrenal glands.

sequence alignments revealed that positions 178 and 246 were highly conserved across species (Fig. 5). Polyphen2 (genetics.bwh.harvard.edu/pph2), SIFT (sift.bii.a-star.edu. sg) and PROVEAN (provean.jcvi.org/genome_submit_2. php?species=human) software predicted the mutations as detrimental (Table III). The computational model used in this study was modified by introducing the missense mutations using the Swiss-Model program (Fig. 6). The tertiary structure before and after the mutation did not alter; however, Gln178 formed a new hydrogen bond with Gly176 and the 
Table III. Results predicted by Polyphen2, SIFT and PROVEAN software.

\begin{tabular}{|c|c|c|c|c|c|c|}
\hline \multirow[b]{2}{*}{ Variant } & \multicolumn{2}{|c|}{ Polyphen2 } & \multicolumn{2}{|c|}{ SIFT } & \multicolumn{2}{|c|}{ PROVEAN } \\
\hline & HumVar score & Prediction & Score & Prediction & Score (cutoff: -2.5 ) & Prediction \\
\hline Leu178Gln & $\begin{array}{l}0.897 \text { (sensitivity, 0.70; } \\
\quad \text { specificity, 0.90) }\end{array}$ & Probably damaging & 0 & Damaging & -3.340 & Deleterious \\
\hline Asp246Gly & $\begin{array}{l}0.989 \text { (sensitivity, 0.52; } \\
\quad \text { specificity, } 0.95 \text { ) }\end{array}$ & Probably damaging & 0 & Damaging & -5.204 & Deleterious \\
\hline
\end{tabular}

SIFT, Sorting Intolerant From Tolerant; PROVEAN, Protein Variation Effect Analyzer.

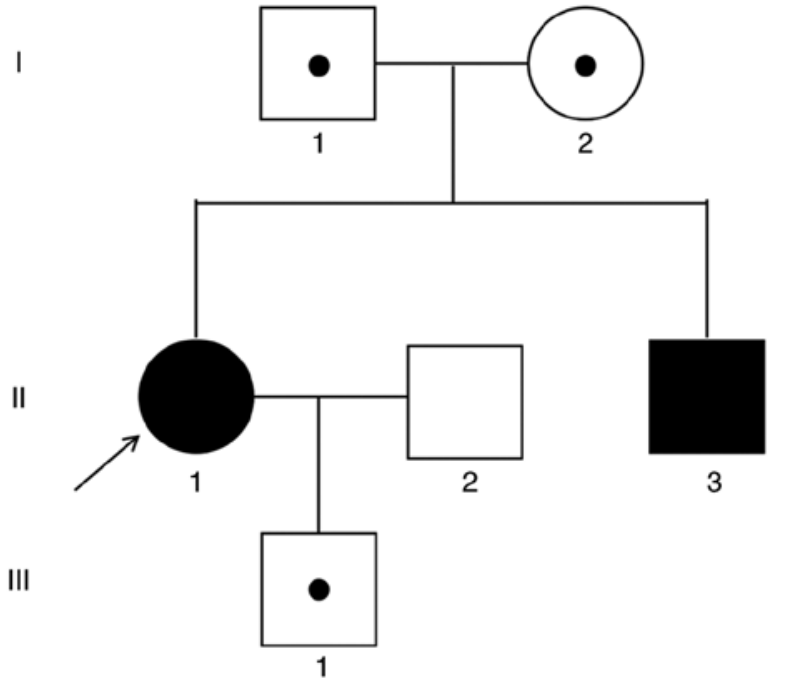

Figure 3. Pedigree of the proband's family. Circles indicate women and squares indicate men. Black symbol, the patients (II: Patient 1; II: Patient 2). Black spots, mutation carriers (I: Asp246Gly; I: Leu178Gln; III: Asp246Gly) and white symbol, normal. The arrow indicates the presence of proband and all heterozygous genotype.

hydrogen bond between Asp246 and Lys248 disappeared after mutation. The skin hyperpigmentation (Fig. 1) and the general state of the two patients was improved after three months of treatment. They also gained weight. The serum cortisol, serum electrolytes and blood glucose were normal, cortisol increased and ACTH decreased significantly in the proband, while the ACTH level in patient 2 was high in the short-term.

\section{Discussion}

The patients included in the present case were siblings, who presented skin hyperpigmentation throughout the body, particularly in hands, lips and nipples. The gonadal development was normal, but laboratory tests suggested glucocorticoid deficiency and mild lack of mineralocorticoid, indicating hyponatremia and hypotension in the proband. The cortisol level was not affected by the stimulation with ACTH and the clinical diagnosis was PAI; however, the adrenal glands did not show any hyperplasia. Gene analysis revealed two novel compound heterozygote mutations c.533T $>$ A (p. Leu178Gln)

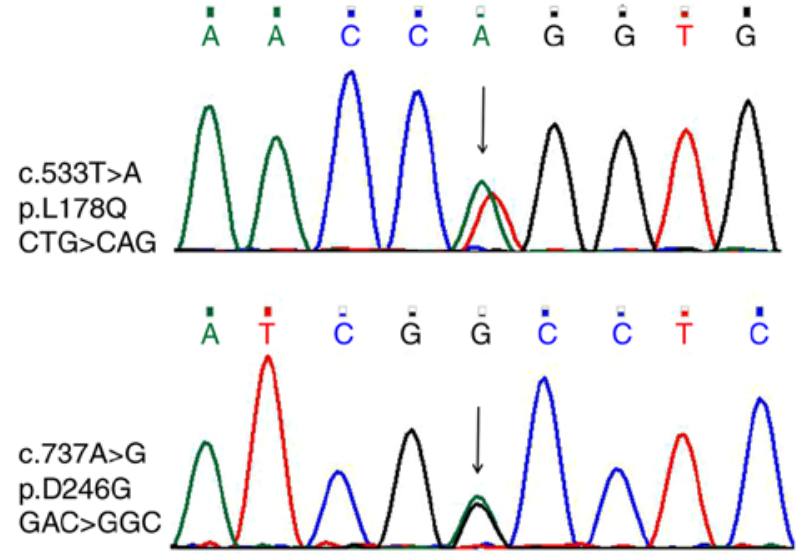

Figure 4. The sequencing peak pattern of the mutations verified by the first generation of gene sequencing. The additional peak indicates the heterozygous genotype.

\begin{tabular}{|c|c|c|}
\hline & p.L178 & p.D246 \\
\hline DANRE & GQETMITHEISAETPGNVVG & WLLSLDLKGWIPKTVINRVL \\
\hline $\mathrm{CHICK}$ & GKDTLITHETAAAPPGNIVG & WLLS IDLKGWLPKT I INQVL \\
\hline RAT & GKDTVITHELAAAAAGNLVG & WLLS IDLKGWLPKT I INQV \\
\hline MOUSE & GKDTVITHELAAAAAGNLVG & WLLS IDLKGWLPKT I INQV \\
\hline HUMAN & GKDTFITHELAAEAAGNUVG & WLLS IDLKGWLPKS I INQV \\
\hline HORSE & GKDTVITHELAAESAGNLVG & WLLS IDLKGWLPKT I INQV \\
\hline BOVIN & GKDTVITHELAAEVAGNLVG & IDLLKGLPKT I INQV \\
\hline SHEEP & GKDT I I THELAAEAAGNLVG & WLLS IDLKGWLPKT I INQV \\
\hline PIG & GKDTV ITHELAAEAAGN凹VG & WLLSIDLKGWLPKT I INQV \\
\hline
\end{tabular}

Figure 5. Amino acid sequence alignments of human and other homologous proteins. The figure represents the partial alignment of STAR sequences of human, chicken, rat, mouse, horse, bovine, sheep and pig around the position of the two mutations (p. Asp246Gly, Leu178Gln), which is denoted by a frame, revealing highly conserved sequences across mammalian species.

and c.737A $>\mathrm{G}$ (p. Asp246Gly) in the STAR gene, which were passed onto the patients, one from each parent, respectively.

In 1994, Clark et al (11) cloned the complementary DNA for a $30-\mathrm{kDa}$ mouse mitochondrial protein that appeared to be rapidly inducible, cycloheximide-sensitive mediator of the acute steroidogenic response, and termed it STAR. STAR is produced as a 285 -amino-acid protein with an $\mathrm{N}$-terminal signal sequence that targets the molecule to the interior of the mitochondria, while the C-terminal STAR-related lipid transfer domain is essential for its function and forms a pocket that might bind cholesterol $(12,13)$. All steroids are derived from pregnenolone, a product of the cholesterol side chain 


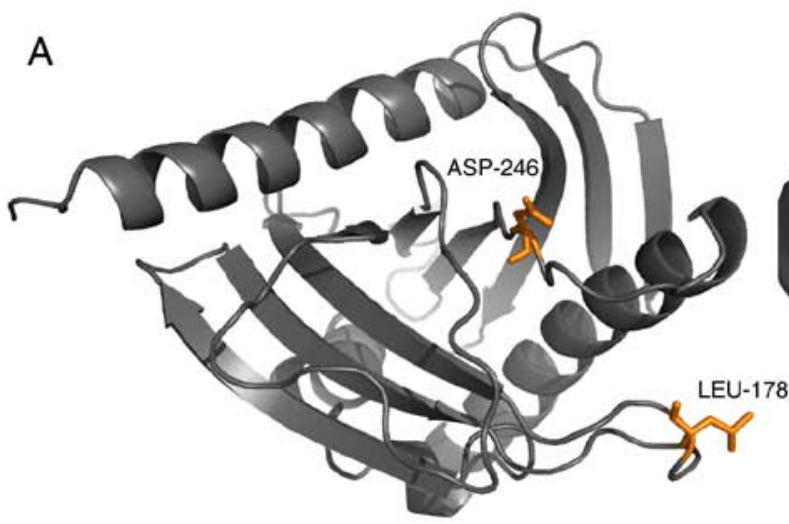

B

C

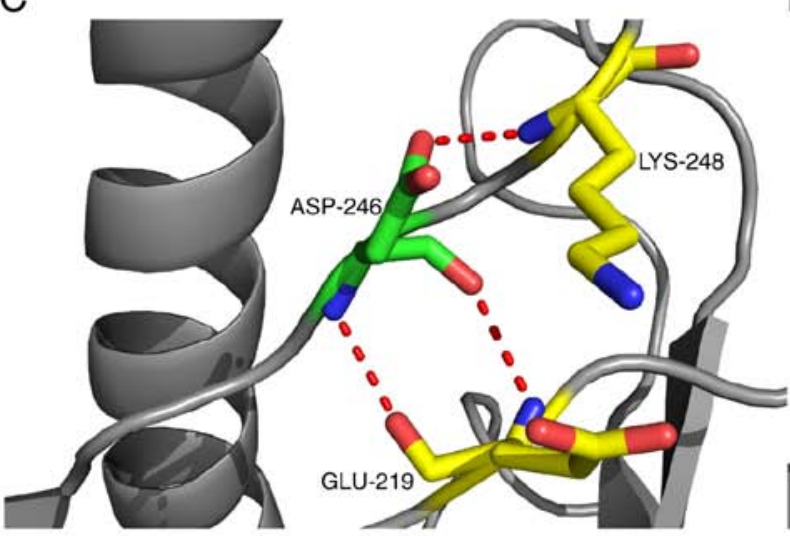

D

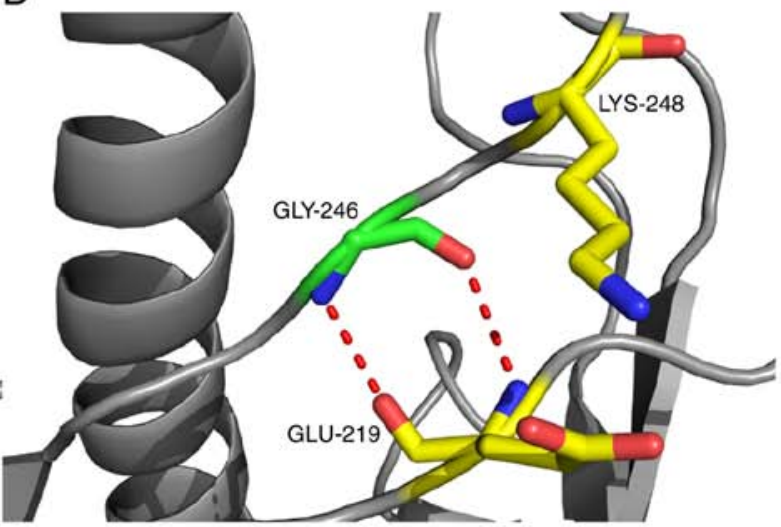

Figure 6. Computational model modified by introducing missense mutations using the Swiss-Model program. (A) The tertiary structure was not altered before and after the mutation, the mutant amino acids p. Asp246Gly, p. Leu178Gln are presented in yellow. (B) Gln178 forms a new hydrogen bond with Gly176 after mutation. (C) The hydrogen bond between Asp246 and Lys248 (D) disappeared after mutation.

cleavage reaction catalyzed by CYP11A (14) and the supply of substrate cholesterol from the outer mitochondrial membrane to this inner mitochondrial membrane enzyme is regulated by STAR. The transfer of cholesterol to P450scc constitutes the rate-limiting step in steroidogenesis. The mutations in the $S T A R$ gene are primarily concentrated in the C-terminal of the protein encoded by exons 5, 6 and 7, causing congenital lipoid adrenal hyperplasia (CLAH), which is the rarest but most severe form of CAH (15). It results from a general loss of all steroid production and is presented as primary adrenal insufficiency or Addison's disease. The symptoms include low body weight, severe dehydration, skin hyperpigmentation, respiratory distress and vomiting in patients.

However, in 2006, Baker et al (16) reported that patients with STAR disorder show a late presentation and normal male genitalia, thus are defined as having a new disorder, 'non-classic LCAH' (NCLAH). This phenomenon represented a new cause of non-autoimmune Addison's disease (primary adrenal failure). In 2009, Metherell et al (7) screened FGD patients from 80 families and revealed homozygous STAR mutations in five families. In addition, the results demonstrated that specific mutations in STAR cause NCLAH masquerading as FGD and present a phenotype indistinguishable from that of FGD. The partial loss-of-function due to STAR mutations was deemed as a cause of type 3 FGD with $\geq 10$ cases of the mutations reported (17).

The study by Baker et al (16) described the FGD-like phenotypes in three patients with mutations, V187M and
$\mathrm{R} 188 \mathrm{C}$, in adjacent codons. The structural modeling of both residues encompassed within the cholesterol-binding pocket of STAR suggested that the R188C mutation would prevent the formation of a salt bridge typically localized between residues E169 and R188 but could result in a weak bond between residues T167 and R188 that may sufficiently preserve the binding pocket to transport the cholesterol. The functional analysis of both V187M and R188C mutants revealed that $>20 \%$ cholesterol binding activity was retained. This residual activity may be ascribed to the cortisol deficiency and mild hyperreninemia in the 2-year-old patients, thereby resembling the patients with FGD. Thus, in the patients of the present study, the mutations Leu178Gln and Asp246Gly, also within the cholesterol-binding pocket of STAR, may exhibit similar mechanisms. The statistical analysis of 10 cases of mutations in the study by Flück et al demonstrated a 3-5\% retention of the cholesterol binding activity and the maximum age of onset was 58 years (17). The low levels of STAR-independent steroidogenesis and a complete loss of steroidogenesis due to cellular destruction by accumulated lipids formed the two-hit model of LCAH (18). Interestingly, the adrenals of both patients in the present case revealed no hyperplasia and patient 1 had unilateral calcification. Furthermore, a previous study had already speculated that the cirrhotic end stage of previous fat deposition resembled the imaging changes observed during progression from steatosis hepatitis to liver cirrhosis, although a precise mechanism has yet to be elucidated (7). 
In summary, two compound heterozygous mutations in the STAR gene in two related patients (sister and brother) with isolated glucocorticoid deficiency were reported. Moreover, lack of mineralocorticoid and normal gonadal function was observed. The proband was preparing for her second child; however, proband and her brother's adrenal function may be further affected after several years, thereby necessitating regular monitoring.

\section{Acknowledgements}

Not applicable.

\section{Funding}

No funding was received.

\section{Availability of data and materials}

The datasets used and/or analyzed during the current study are available from the corresponding author on reasonable request.

\section{Authors' contributions}

YL, RB, XZ and JX acquired, analyzed and interpreted the data. $Y L$ drafted the manuscript, figures and table, and revised the manuscript. RB drafted the manuscript. ZW made substantial contributions to the conception and design of the study, and critically revised the manuscript for important intellectual content. XL made substantial contributions to the conception and design of the study, and approved the final version of the manuscript. All authors approved the final version of the manuscript.

\section{Ethics approval and consent to participate.}

The present study was approved by the Scientific Research and Clinical Trials Ethics Committee of the First Affiliated Hospital of Zhengzhou University (approval no. 2019-005). Written informed consent was obtained from the participants and the parent of the son of the proband.

\section{Patient consent for publication}

Written informed consent for the publication of the data presented in the present study was obtained from the participants and the parent of the son of the proband.

\section{Competing interests}

The authors declare that they have no competing interests.

\section{References}

1. Shepard TH, Landing BH and Mason DG: Familial Addison's disease; case reports of two sisters with corticoid deficiency unassociated with hypoaldosteronism. AMA J Dis Child 97: 154-162, 1959.

2. Clark AJ, McLoughlin L and Grossman A: Familial glucocorticoid deficiency associated with point mutation in the adrenocorticotropin receptor. Lancet 341: 461-462, 1993.
3. Metherell LA, Chapple JP, Cooray S, David A, Becker C, Rüschendorf F, Naville D, Begeot M, Khoo B, Nürnberg P, et al: Mutations in MRAP, encoding a new interacting partner of the ACTH receptor, cause familial glucocorticoid deficiency type 2 . Nat Genet 37: 166-170, 2005.

4. Meimaridou E, Kowalczyk J, Guasti L, Hughes CR, Wagner F, Frommolt P, Nürnberg P, Mann NP, Banerjee R, Saka HN, et al: Mutations in NNT encoding nicotinamide nucleotide transhydrogenase cause familial glucocorticoid deficiency. Nat Genet 44: 740-742, 2012.

5. Hughes CR, Guasti L, Meimaridou E, Chuang CH, Schimenti JC, King PJ, Costigan C, Clark AJ and Metherell LA: MCM4 mutation causes adrenal failure, short stature and natural killer cell deficiency in humans. J Clin Invest 122: 814-820, 2012.

6. Prasad R, Chan LF, Hughes CR, Kaski JP, Kowalczyk JC, Savage MO, Peters CJ, Nathwani N, Clark AJ, Storr HL and Metherell LA: Thioredoxin Reductase 2 (TXNRD2) mutation associated with familial glucocorticoid deficiency (FGD). J Clin Endocrinol Metab 99: E1556-E1563, 2014.

7. Metherell LA, Naville D, Halaby G, Begeot M, Huebner A, Nürnberg G, Nürnberg P, Green J, Tomlinson JW, Krone NP, et al: Nonclassic lipoid congenital adrenal hyperplasia masquerading as familial glucocorticoid deficiency. J Clin Endocrinol Metab 94: 3865-3871, 2009.

8. Flück CE, Tajima T, Pandey AV, Arlt W, Okuhara K, Verge CF, Jabs EW, Mendonça BB, Fujieda K and Miller WL: Mutant P450 oxidoreductase causes disordered steroidogenesis with and without Antley-Bixler syndrome. Nat Genet 36: 228-230, 2004.

9. Bose HS, Pescovitz OH and Miller WL: Spontaneous feminization in a $46, \mathrm{XX}$ female patient with congenital lipoid adrenal hyperplasia due to a homozygous frameshift mutation in the steroidogenic acute regulatory protein. J Clin Endocrinol Metab 82: 1511-1515, 1997.

10. Fujieda K, Tajima T, Nakae J, Sageshima S, Tachibana K, Suwa S, Sugawara T and Strauss JF III: Spontaneous puberty in 46,XX subjects with congenital lipoid adrenal hyperplasia. Ovarian steroidogenesis is spared to some extent despite inactivating mutations in the steroidogenic acute regulatory protein (StAR) gene. J Clin Invest 99: 1265-1271, 1997.

11. Clark BJ, Wells J, King SR and Stocco DM: The purification, cloning, and expression of a novel luteinizing hormone-induced mitochondrial protein in MA-10 mouse Leydig tumor cells. Characterization of the steroidogenic acute regulatory protein (StAR). J Biol Chem 269: 28314-28322, 1994.

12. King SR, Ronen-Fuhrmann T, Timberg R, Clark BJ, Orly J and Stocco DM: Steroid production after in vitro transcription, translation, and mitochondrial processing of protein products of complementary deoxyribonucleic acid for steroidogenic acute regulatory protein. Endocrinology 136: 5165-5176, 1995.

13. Tsujishita Y and Hurley JH: Structure and lipid transport mechanism of a StAR-related domain. Nat Struct Biol 7: 408-414, 2000.

14. Stocco DM and Clark BJ: Regulation of the acute production of steroids in steroidogenic cells. Endocr Rev 17: 221-244, 1996.

15. Bhangoo A, Anhalt H, Ten S and King SR: Phenotypic variations in lipoid congenital adrenal hyperplasia. Pediatr Endocrinol Rev 3: 258-271, 2006.

16. Baker BY, Lin L, Kim CJ, Raza J, Smith CP, Miller WL and Achermann JC: Nonclassic congenital lipoid adrenal hyperplasia: A new disorder of the steroidogenic acute regulatory protein with very late presentation and normal male genitalia. J Clin Endocrinol Metab 91: 4781-4785, 2006.

17. Flück CE, Pandey AV, Dick B, Camats N, Fernández-Cancio M, Clemente M, Gussinyé M, Carrascosa A, Mullis PE and Audi L: Characterization of novel StAR (steroidogenic acute regulatory protein) mutations causing non-classic lipoid adrenal hyperplasia. PLoS One 6: e20178, 2011.

18. Miller WL: Mitochondrial specificity of the early steps in steroidogenesis. J Steroid Biochem Mol Biol 55: 607-616, 1995.

This work is licensed under a Creative Commons Attribution-NonCommercial-NoDerivatives 4.0 International (CC BY-NC-ND 4.0) License. 